University of Nebraska - Lincoln

DigitalCommons@University of Nebraska - Lincoln

Faculty Publications from Nebraska Center for

Materials and Nanoscience

Materials and Nanoscience, Nebraska Center

for $(\mathrm{NCMN})$

December 2004

\title{
Imaging using lateral bending modes of atomic force microscope cantilevers
}

A. Caron

Fraunhofer Institute for Non-Destructive Testing, Building 37, University, D-66123 Saarbrücken, Germany

U. Rabe

Fraunhofer Institute for Non-Destructive Testing, Building 37, University, D-66123 Saarbrücken, Germany

M. Reinstadtler

Fraunhofer Institute for Non-Destructive Testing, Building 37, University, D-66123 Saarbrücken, Germany

Joseph A. Turner

University of Nebraska - Lincoln, jaturner@unl.edu

W. Arnold

Fraunhofer Institute for Non-Destructive Testing, Building 37, University, D-66123 Saarbrücken, Germany

Follow this and additional works at: https://digitalcommons.unl.edu/cmrafacpub

Part of the Nanoscience and Nanotechnology Commons

Caron, A.; Rabe, U.; Reinstadtler, M.; Turner, Joseph A.; and Arnold, W., "Imaging using lateral bending modes of atomic force microscope cantilevers" (2004). Faculty Publications from Nebraska Center for Materials and Nanoscience. 52.

https://digitalcommons.unl.edu/cmrafacpub/52

This Article is brought to you for free and open access by the Materials and Nanoscience, Nebraska Center for (NCMN) at DigitalCommons@University of Nebraska - Lincoln. It has been accepted for inclusion in Faculty Publications from Nebraska Center for Materials and Nanoscience by an authorized administrator of DigitalCommons@University of Nebraska - Lincoln. 


\title{
Imaging using lateral bending modes of atomic force microscope cantilevers
}

\author{
A. Caron, U. Rabe, and M. Reinstädtler \\ Fraunhofer Institute for Non-Destructive Testing, Building 37, University, D-66123 Saarbrücken, Germany \\ J. A. Turner \\ Department of Engineering Mechanics, University of Nebraska, W317.4 Nebraska Hall, Lincoln, Nebraska \\ 68588-0526 \\ W. Arnold ${ }^{\mathrm{a})}$ \\ Fraunhofer Institute for Non-Destructive Testing, Building 37, University, D-66123 Saarbrücken, Germany
}

(Received 8 July 2004; accepted 27 October 2004)

\begin{abstract}
Using scanning probe techniques, surface properties such as shear stiffness and friction can be measured with a resolution in the nanometer range. The torsional deflection or buckling of atomic force microscope cantilevers has previously been used in order to measure the lateral forces acting on the tip. This letter shows that the flexural vibration modes of cantilevers oscillating in their width direction parallel to the sample surface can also be used for imaging. These lateral cantilever modes exhibit vertical deflection amplitudes if the cantilever is asymmetric in thickness direction, e.g., by a trapezoidal cross section. (C) 2004 American Institute of Physics. [DOI: 10.1063/1.1833553]
\end{abstract}

The atomic force microscope $(\mathrm{AFM})^{1}$ has found wide applications in biology, physics, and material science. Most AFM operation modes measure the deflection of the cantilever caused by the forces acting vertically between the tip and the sample while it is scanned. This allows mapping of surface properties such as topography, elasticity, magnetic or piezoelectric domains and other quantities with nanometer resolution. Both lateral and vertical forces contribute to the total tip-sample interaction. ${ }^{2}$ In friction force microscopy lateral tip-sample forces are measured. ${ }^{3}$ In early experiments the lateral deflection of a bent tungsten wire ${ }^{4}$ or the buckling of the cantilever in its length direction ${ }^{5}$ was exploited to image atomic-scale friction. In commercial AFMs friction and lateral forces are detected by measuring the torsion of AFM cantilevers. Here, a new mode of atomic force acoustic microscopy (AFAM) ${ }^{6}$ is discussed. In AFAM the flexural ${ }^{6}$ or torsional $^{2}$ resonance frequencies of AFM cantilevers in contact with a sample surface are measured. We show that it is possible to image local variation in shear elastic properties by exciting the flexural resonances of the cantilever polarized in its width direction with the sensor tip in sample contact. We present briefly the AFAM technique followed by a discussion of the lateral resonance mode. Then images obtained on a polycrystalline stabilized zirconia are presented.

In the AFAM technique an AFM cantilever is set into flexural oscillations either by out-of-plane movements of the sample $^{6-8}$ caused by ultrasonic waves or by exciting the chip of the cantilever. ${ }^{9}$ The oscillations are detected by the optical beam-deflection scheme of an AFM. Since the contact resonance frequency depends on the tip-sample contact stiffness, variations of local elasticity lead to a shift of the resonance frequency. This shift can either be used to measure quantitatively the local contact stiffness or to image variation in elastic properties. ${ }^{6-12}$ By insonifying ultrasonic shear waves into the sample causing in-plane surface displacements, torsional resonances of the AFM cantilevers were excited, offering the

${ }^{\text {a) Electronic mail: arnold@izfp.fhg.de }}$ possibility to gain information on frictional properties or shear elasticity. ${ }^{2}$

Using a scanning interferometer, ${ }^{13}$ we examined the vibration spectra of cantilevers made of single crystal silicon with approximately rectangular shape. We noticed that eigenmodes of the cantilever can be excited by in-plane displacements which are neither torsional nor flexural modes. The frequencies of all eigenmodes up to $3 \mathrm{MHz}$ of one sensor used by us (type FM manufactured by Nanosensors GmbH, Erlangen, Germany) are listed in Table I. We found a third kind of eigenmode at a frequency located between the second free flexural and the first torsional modes. Figures 1(a)-1(d) show amplitudes and phases of the oscillations of two cantilever modes measured with the optical interferometer. The cantilever was not in contact with a sample surface. Its suspension was located at the left-hand side of the images.

Finite-element calculations were carried out to identify this unknown mode. The beam was assumed to be free at one end and rigidly clamped at the other end. Due to the etching process during manufacturing the cantilevers have a trapezoidal instead of a rectangular cross section. A lateral mode is an in-plane flexural mode vibrating parallel to the width of the cantilever (here in the $y$ direction). Even a beam with rectangular cross section displays a small out-of-plane component $z$ with a ratio $z / y=5.7 \times 10^{-4}$ for the lateral mode $L_{1}$ due to transverse contraction and expansion [Fig. 1(e)]. Assuming a trapezoidal cross section, the calculated out-ofplane component of $L_{1}$ becomes much higher and $z / y$ is now $5.8 \times 10^{-2}$ [Fig. 1(f)]. The $z / y$ ratio for the first torsional mode $T_{1}$ is 17 with the same trapezoidal cross section [Fig. $1(\mathrm{~g})]$. A colored and animated version of Fig. 1 is available (see EPAPS Ref. 14).

In-plane motion cannot be detected with the optical interferometer we used or with the built-in optical beamdeflection of an AFM. However, an asymmetry like the trapezoidal cross section leads to a $z$ component of the displacement allowing the detection of the lateral modes. Amplitude and phase of the first lateral mode are similar to 
TABLE I. Experimental and calculated resonance frequencies of a single crystal silicon cantilever with the dimensions $239.5 \times 29 \times 3.3 \mu \mathrm{m}^{3}$ (length $\times$ width $\times$ thickness). The width is the mean value of the upper and the lower width of the trapezoid. For the calculations a Young's modulus of $169 \mathrm{GPa}$ and a shear modulus of $50.9 \mathrm{GPa}$ were used. The equations for calculating the torsional or flexural resonance frequencies can be found in Refs. 2 and 6.

\begin{tabular}{lccccccc}
\hline \hline & $\begin{array}{c}\text { First } \\
\text { flexural } \\
\text { mode }\end{array}$ & $\begin{array}{l}\text { Second } \\
\text { flexural } \\
\text { mode }\end{array}$ & $\begin{array}{l}\text { First } \\
\text { lateral } \\
\text { mode }\end{array}$ & $\begin{array}{l}\text { First } \\
\text { torsional } \\
\text { mode }\end{array}$ & $\begin{array}{l}\text { Third } \\
\text { flexural } \\
\text { mode }\end{array}$ & $\begin{array}{l}\text { Fourth } \\
\text { flexural } \\
\text { mode }\end{array}$ & $\begin{array}{l}\text { Second } \\
\text { torsional } \\
\text { mode }\end{array}$ \\
\hline $\begin{array}{l}\text { Experimentally } \\
\text { observed } \\
\text { frequency }(\mathrm{kHz})\end{array}$ & 79.5 & 501 & 631 & 1111 & 1410 & 2765 & 3342 \\
$\begin{array}{l}\text { Calculated } \\
\text { frequency }(\mathrm{kHz})\end{array}$ & 79.1 & 496 & 695 & 1110 & 1399 & 2721 & 3331 \\
\hline \hline
\end{tabular}

the amplitude and phase of the first torsional mode. The slight difference in frequency between experiment and simulation is mainly caused by the cantilever suspension, which is not perfectly rigid and symmetric as assumed in the simulations. Lateral modes of rectangular beams show $z$ displacements similar to the one shown in Fig. 1(f) as well when an elastic and asymmetric suspension is included in the model.

The eigenfrequencies $f_{n}, n=\{1,2,3, \ldots\}$ of the flexural modes of a clamped-free cantilever with rectangular cross section are $^{6}$

$$
f_{n}=\frac{\left(k_{n} L\right)^{2}}{2 \pi L^{2}} / \sqrt{\frac{\rho A}{E I}},
$$

with $I=a b^{3} / 12$. Here, $E$ is the Young's modulus, $\rho$ is the density, $A$ is the cross section of the cantilever, $L$ is its length, and $a$ and $b$ are the thickness and the width of the cantilever, respectively. The wave numbers $k_{n}$ are the solu-
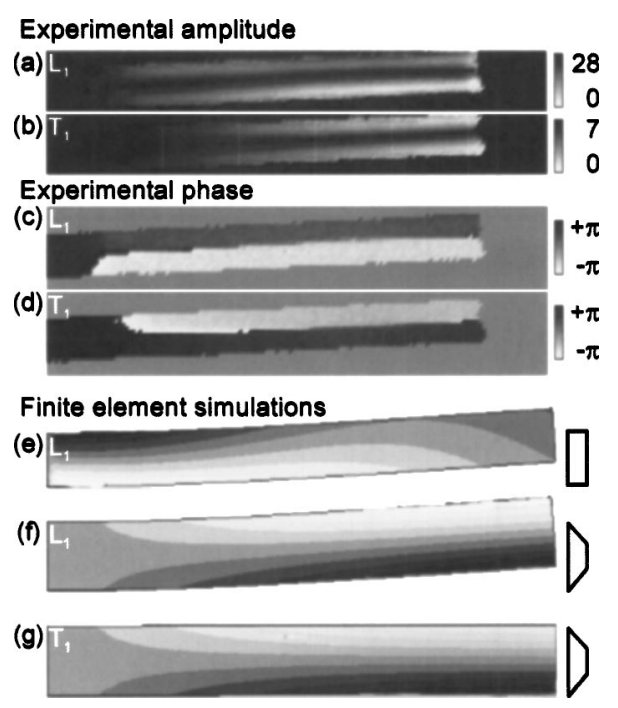

FIG. 1. Interferometrically measured amplitude and phase distribution of a free cantilever [(a)-(d)] and finite-element simulations [(e), (f)]. The first lateral $\left(L_{1}\right)$ and torsional modes $\left(T_{1}\right)$ were measured at a frequency of 583 and $1003 \mathrm{kHz}$, respectively. The finite-element simulations were carried out with a cantilever thickness of $2.9 \mu \mathrm{m}$ and a length of $241 \mu \mathrm{m}$. In the grey scales, white means a negative and black a positive displacement in thickness direction. (e) The lateral mode $\left(L_{1}, 605 \mathrm{kHz}\right)$ in the case of a rectangular beam cross section of $26 \mu \mathrm{m}$ width. (f), (g) The first lateral mode $\left(L_{1}\right.$, $631 \mathrm{kHz})$ and the torsional mode $\left(T_{1}, 983 \mathrm{kHz}\right)$ for the trapezoidal cross section. The lengths of the narrow and wide side of the trapeze were 18 and $33.5 \mu \mathrm{m}$, respectively. The finite-element simulations were processed with ANSYS 7.1 by using approximately 2000 tetraeder shaped elements of the type Solid 187. tions of the characteristic equation $\cos \left(k_{n} L\right) \cosh \left(k_{n} L\right)=-1$. For lateral modes Eq. (1) holds as well when $a$ and $b$ are exchanged. The theoretical flexural resonance frequencies according to Eq. (1) are shown in Table I.

We also examined whether the lateral resonances shift in frequency with applied force with the tip in sample contact. Figure 2 shows the contact resonance frequency as a function of the applied force for the first lateral mode. The resonance frequency of the lateral mode increases with static load, although only slightly. Moreover one can observe that the resonance amplitude significantly increases with load because the contact area increases, and that for loads up to $200 \mathrm{nN}$ the width of the resonance curve is larger than for still higher loads, i.e., $Q$ is smaller. At present we surmise that sliding friction occurs between the tip and the sample which is suppressed at larger static loads. ${ }^{15}$ We will examine this in more detail.

In the AFAM imaging mode one works at a fixed frequency near the cantilever contact-resonance. A shift of the resonance frequency leads to a variation of the oscillation amplitude, allowing one to image local variations of elastic properties. An important difference between imaging with vertical and lateral excitation of the cantilever resides in the fact that scanning with a flexural mode maps local variations of the reduced Young's modulus defined as $E^{\prime}=E /\left(1-\nu^{2}\right){ }^{3}$ whereas scanning with a lateral-mode contact resonance maps local changes in the reduced shear modulus defined as $G^{\prime}=G /\left(1-\nu^{2}\right)$. Here, $E$ is the Young's modulus, $\nu$ is the Poisson ratio, and $G$ is the shear modulus. Figure 3(a) shows a topography image and the corresponding AFAM images [(b)-(d)] at the same position of a stabilized 3\% mol yttrium zircon oxide sample. The lateral AFAM image recorded at a frequency of $685 \mathrm{kHz}$ is compared to an AFAM image obtained with the first flexural mode $(380 \mathrm{kHz})$ and to the first

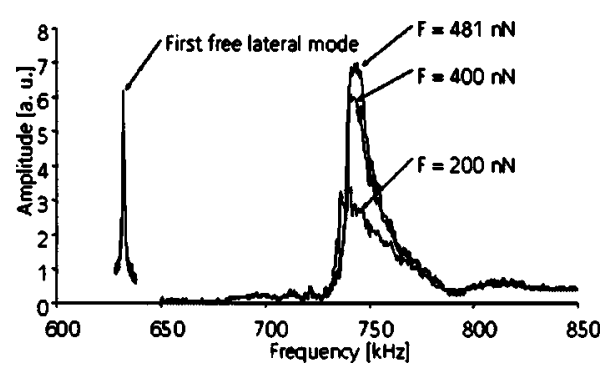

FIG. 2. Resonance curve for the first free lateral mode measured with an optical interferometer and contact resonances of the same cantilever as a function of applied load $F$ on the 3Y-TZP stabilized zirconia sample. 


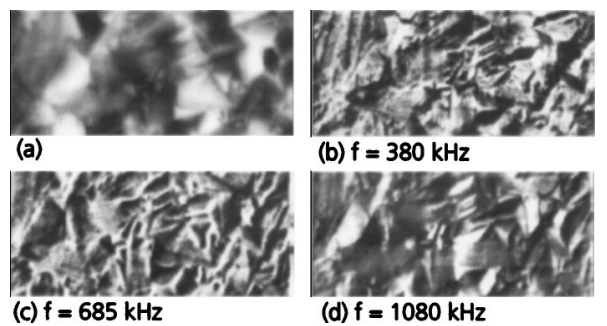

FIG. 3. Topography (a) and AFAM images obtained with a first flexural (b), first lateral (c), first torsional (d) mode, respectively, at the indicated contact frequencies of a 3 Y-TZP stabilized zirconia sample with an average grain size of $500 \mathrm{~nm}$. Image sizes are $1.3 \times 3 \mu \mathrm{m}^{2}$ and the images were taken at the same location. The nominal spring constant of the cantilever employed was $3.9 \mathrm{~N} / \mathrm{m}$ and the static force applied during imaging was $280 \mathrm{nN}$.

torsional mode $(1080 \mathrm{kHz})$. The resonance frequency for the first lateral mode shifted between taking images and measuring the contact resonance. From our experience we know that during imaging the tip often gets worn while being scanned, which in turn increases the contact radius and hence the contact stiffness.

In contrast to torsional cantilever deflections, where the tip movement covers a circle segment, for lateral cantilever deflections the movement of the sensor tip-axis remains mainly parallel to the sample surface. This means that the vertical tip-sample distance remains constant during a lateral vibration cycle, and lateral modes should therefore be sensitive to in-plane surface properties. We expect that imaging of frictional properties will be possible when the lateral amplitudes become so large that they surmount the static friction forces between tip and sample, similar to the observations obtained with torsional resonances. ${ }^{15}$ In summary, our experiments have shown that in AFM measurements in-plane deflection of standard cantilevers is not negligible, which has recently been reported for the case of static deflections as well. ${ }^{16}$

The authors are thankful for grants from the German Ministry of Education, Science and Technology, the German Science Foundation within the Materials Science Graduate College at the University of the Saarland. J.A.T. is supported by the National Science Foundation (Grant Nos. DMI0210850, INT-0089548). The authors also thank the German Academic Exchange Service for supporting the collaboration between UNL and the IZFP. It is a pleasure to thank C. Deutscher, U. Eberlein, and K. Reinstädtler for skillful measurements of the oscillatory behavior of the cantilevers using optical interferometry. J. Rödel from the Technical University of Darmstadt is acknowledged for collaboration on the fracture mechanics of polycrystalline yttrium stabilized zirconia and for fruitful discussions.

${ }^{1}$ G. Binning, C. F. Quate, and Ch. Gerber, Phys. Rev. Lett. 56, 930 (1986).

${ }^{2}$ V. Scherer, M. Reinstaedtler, and W. Arnold, in Applied Scanning Probe Methods, edited by H. Fuchs, B. Bhushan, and S. Hosaka (Springer, Berlin, 2003), pp. 76-115, and references therein.

${ }^{3}$ B. Bhushan, in Handbook of Nanotechnology, edited by B. Bhushan (Springer, Berlin, 2004), pp. 497ff, and references therein.

${ }^{4}$ C. M. Mate, G. M. McClelland, R. Erlandsson, and S. Chiang, Phys. Rev. Lett. 59, 1942 (1987).

${ }^{5}$ T. Göddenhenrich, S. Müller, and C. Heiden, Rev. Sci. Instrum. 65, 2870 (1994).

${ }^{6}$ U. Rabe, K. Janser, and W. Arnold, Rev. Sci. Instrum. 67, 3281 (1996).

${ }^{7}$ U. Rabe, S. Amelio, E. Kester, V. Scherer, S. Hirsekorn, and W. Arnold, Ultrasonics 38, 430 (2000).

${ }^{8}$ D. C. Hurley, K. Shen, N. M. Jennett, and J. A. Turner, J. Appl. Phys. 94, 2347 (2003).

${ }^{9}$ A. E. Efimov, S. A. Saunin, and N. A. Mescheryakov, in Acoustical Imaging, edited by W. Arnold and S. Hirsekorn (Kluwer Academic, Dordrecht, 2004), Vol. 27, pp. 729-733.

${ }^{10}$ K. Yamanaka and S. Nakano, Jpn. J. Appl. Phys., Part 1 35, 93 (1996).

${ }^{11}$ K. Yamanaka, A. Noguchi, T. Tsuij, T. Koike, and T. Goto, Surf. Interface Anal. 27, 600 (1999).

${ }^{12}$ M. Kopycinska-Müller, M. Reinstädtler, U. Rabe, A. Caron, S. Hirsekorn, and W. Arnold, in Ref. 9, pp. 699-706.

${ }^{13}$ M. Reinstaedtler, U. Rabe, V. Scherer, J. A. Turner, and W. Arnold, Surf. Sci. 532, 1152 (2003).

${ }^{14}$ See EPAPS Document No. E-APPLAB-85-069450 for colored versions of Fig. 1. A direct link to this document may be found in the online article's HTML reference section. The document may also be reached via the EPAPS homepage (http://www.aip.org/org/pubservs/epaps.html) or from ftp.aip.org in the directory /epaps/. See the EPAPS homepage for more information.

${ }^{15}$ M. Reinstaedtler, U. Rabe, V. Scherer, U. Hartmann, A. Goldade, B. Bhushan, and W. Arnold, Appl. Phys. Lett. 82, 2604 (2003).

${ }^{16}$ J. E. Sader and C. P. Green, Rev. Sci. Instrum. 75, 878 (2004). 